\title{
P02.78. Treating pediatric asthma with holistic approaches of traditional Chinese medicine
}

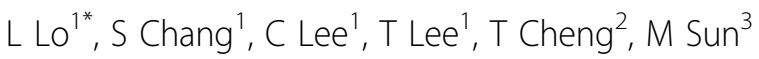 \\ From International Research Congress on Integrative Medicine and Health 2012 \\ Portland, Oregon, USA. 15-18 May 2012
}

\section{Purpose}

Asthma is a chronic disease increasingly found in children. In order to find more economical and efficient alternatives to treat pediatric asthma, the Bureau of National Health Insurance of Taiwan launched the Traditional Chinese Medicine Holistic Treatment Program (TCMHTP). Based on the data collected during the program, we evaluated the effect of TCM holistic treatments on pediatric asthma.

\section{Methods}

We performed a retrospective study by analyzing a dataset from Changhua Christian Hospital in Taiwan during January 1, 2006 and December 1, 2010. Patients aged between 2 and 15 years old who were diagnosed with asthma and have participated in TCMHTP were recruited, while those with other severe diseases were excluded. We analyzed the frequency of emergency department visits (EDV), inpatient admission rate (IAR), and length of hospitalization (LH) of the patients before and after TCM treatments. We also carried out spectral analysis of heart rate variability (HRV).

\section{Results}

Fifty-eight patients were recruited. The average age of the patients receiving TCM treatments is $5.67 \pm 3.03$ years old. The frequency of EDV reduced from $0.97 \pm 0.85$ to $0.69 \pm 1.22$ times annually $(\mathrm{p}=0.095)$, the IAR decreased from $0.86 \pm 0.81$ to $0.36 \pm 0.77$ times annually $(\mathrm{p}=0.001)$ and the average $\mathrm{LH}$ reduced from $4.59 \pm 4.43$ to $1.10 \pm 1.86$ $(\mathrm{p}=0.000)$ days per year. Parasympathetically mediated HRV reduced significantly from $60.42 \pm 15.33$ to $54.89 \pm$ $16.45 \mathrm{nu}(\mathrm{p}=0.016)$.

${ }^{1}$ Changhua Christian Hospital, Department of Chinese Medicine, Changhua City, Taiwan

Full list of author information is available at the end of the article

\section{Conclusion}

In the present study, we found that an appropriate period of TCM holistic treatment intervention can not only significantly lower exacerbations and hospitalization frequency but also decrease vagal tone of the asthmatic children.

\section{Author details}

${ }^{1}$ Changhua Christian Hospital, Department of Chinese Medicine, Changhua City, Taiwan. ${ }^{2}$ National Changhua University of Education, Changhua City, Taiwan. ${ }^{3}$ China Medical University Hospital, Taichung, Taiwan.

Published: 12 June 2012

doi:10.1186/1472-6882-12-S1-P134

Cite this article as: Lo et al:: P02.78. Treating pediatric asthma with holistic approaches of traditional Chinese medicine. BMC Complementary and Alternative Medicine 2012 12(Suppl 1):P134.

\section{Submit your next manuscript to BioMed Central and take full advantage of: \\ - Convenient online submission \\ - Thorough peer review \\ - No space constraints or color figure charges \\ - Immediate publication on acceptance \\ - Inclusion in PubMed, CAS, Scopus and Google Scholar \\ - Research which is freely available for redistribution

C Biomed Central

() 2012 Lo et al; licensee BioMed Central Ltd. This is an Open Access article distributed under the terms of the Creative Commons Attribution License (http://creativecommons.org/licenses/by/2.0), which permits unrestricted use, distribution, and reproduction in any medium, provided the original work is properly cited. 